\title{
Polyhydramnios - frequency of congenital anomalies in relation to the value of the amniotic fluid index
}

\author{
Jakub Kornacki, Magdalena Adamczyk, Przemysław Wirstlein, \\ Maciej Osiński, Ewa Wender-Ożegowska \\ Division of Reproduction, Department of Obstetrics, Gynaecology, and Gynaecologic Oncology, \\ Poznan University of Medical Sciences, Poznan, Poland
}

\begin{abstract}
Objectives: The aims of our study were to assess the correlation between the amniotic fluid index (AFI) value and the frequency and type of fetal anomalies.

Material and methods: The material included 94 patients at the third trimester of pregnancy, 60 with mild polyhydramnios, 19 with moderate one, and 15 with severe one. Polyhydramnios was diagnosed if AFI was $>24 \mathrm{~cm}$. All patients were divided into three groups based on the value of AFI: 1) mild polyhydramnios with AFI between 24.1 and $29.9 \mathrm{~cm}, 2$ ) moderate polyhydramnios with AFI between $30-34.9 \mathrm{~cm}$, and 3) severe polyhydramnios with $\mathrm{AFI} \geq 35 \mathrm{~cm}$.

Results: The incidence of fetal malformations correlated significantly with the degree of polyhydramnios and was the highest in patients with severe polyhydramnios $(53.3 \%, p=0.002)$. Congenital malformations of the gastrointestinal tract were the most frequent fetal anomalies in the whole group of patients (5.3\%). Trisomy 18 was the most frequent aneuploidy found in women with polyhydramnios (2.1\%).
\end{abstract}

Conclusions:

1. The incidence of fetal congenital anomalies significantly increases with the degree of polyhydramnios, being most frequent in severe one and rather rare in a mild one.

2. Congenital malformations of the gastrointestinal tract were the most frequent anomalies in patients with polyhydramnios, especially in women with severe polyhydramnios.

Key words: fetal ultrasound, fetal malformations, gastrointestinal tract, central nervous system

Ginekologia Polska 2017; 88, 8: 442-445

\section{INTRODUCTION}

Polyhydramnios, which is an increased amount of amniotic fluid, complicates approximately $1-2 \%$ of all pregnancies [1,2]. The diagnosis is made by two-dimensional ultrasound finding of the amniotic fluid index (AFI) $>24 \mathrm{~cm}$ or the maximal amniotic pocket (MAP) $>8 \mathrm{~cm}$ [3]. Increased value of MAP is the only criterion to diagnose polyhydramnios in multiple pregnancy.

Fetal congenital anomalies are among the most frequent causes of polyhydramnios, including gastrointestinal tract anomalies, central nervous system defects, musculoskeletal anomalies, airway malformation and congenital diaphragmatic hernia (CDH) [3].

It seems that not only the finding of polyhydramnios, but also the value of AFI have a significant effect on a fetal and neonatal outcome, including the frequency of birth defects $[3,4]$. Congenital anomalies were most frequently found in pregnancies complicated by severe polyhydramnios [4].

\section{OBJECTIVES}

The main aim of our study was to assess the correlation between the AFI value and the frequency of fetal anomalies. The second aim was to analyse the type of malformations and its association with the degree of polyhydramnios.

\section{MATERIAL AND METHODS}

This was a retrospective study conducted among patients, at the third trimester of pregnancy, hospitalized between the years 2008 and 2016 at Division of Reproduction 
of Poznań University of Medical Sciences, in whom polyhydramnios was diagnosed.

Polyhydramnios was diagnosed if the AFI was $>24 \mathrm{~cm}$. If more results of the AFI from one patient were obtained, the maximal value of the AFI was taken. All patients were divided into three groups based on the value of AFI: 1) mild polyhydramnios with AFI between 24.1 and $29.9 \mathrm{~cm}, 2$ ) moderate polyhydramnios with AFI between 30 and $34.9 \mathrm{~cm}$, and 3) severe polyhydramnios with $\mathrm{AFI} \geq 35 \mathrm{~cm}$.

The material included 94 patients, 60 with mild polyhydramnios, 19 with moderate one, and 15 with severe one.

An eventual presence of fetal malformations, type of fetal anomalies and other clinical characteristics including the presence of congenital infection and pre- or gestational diabetes were analyzed.

Statistical analysis was performed using SigmaStat 3.5 (Systat Software Inc). For parametric variables, one way analysis of variance (ANOVA) test was used. For non-parametric variables Kruskal-Wallis one way ANOVA on ranks test with pairwise multiple comparison procedures (Dunn's method) was used. To analyze the distribution of quality characteristics, chi-square and Freeman-Halton extension of Fisher's exact test were used. A $p$-value $<0.05$ was considered to be statistically significant.

\section{RESULTS}

Most of the patients (63.8\%) were diagnosed with mild polyhydramnios, $20.2 \%$ with moderate one, and nearly $16 \%$ with severe one.

The mean value of AFI was $39 \mathrm{~cm}(35-51)$ in a severe polyhydramnios group, $32 \mathrm{~cm}(34.5-40)$ in a moderate polyhydramnios group, and $26 \mathrm{~cm}$ (24-30) in patients with mild polyhydramnios.

In $68.1 \%$ of patients idiopathic polyhydramnios was diagnosed, most frequently in women with mild polyhydramnios (82.6\%). Congenital infection by Toxoplasma gondi was found only in two patients with mild polyhydramnios. The frequency of diabetes did not differ between groups, but was the most frequent among patients with moderate polyhydramnios. Gestational age at delivery was not statistically different among the three groups of patients. The clinical characteristics of patients are presented in Table 1.

The general frequency of fetal anomalies in the studied group of patients with polyhydramnios was $21.3 \%$, including $11.7 \%$ in patients with mild polyhydramnios, $26.3 \%$ in patients with moderate polyhydramnios and $53.3 \%$ in patients with severe polyhydramnios. The incidence of fetal malformations correlated significantly with the degree of polyhydramnios $(p=0.002$, Figure 1$)$.

Table 1. Clinical characteristics of patients with polyhydramnios

\begin{tabular}{|c|c|c|c|c|}
\hline & $\begin{array}{l}\text { Mild polyhydramnios } \\
\qquad(n=60)\end{array}$ & $\begin{array}{l}\text { Modereate polyhydramnios } \\
\qquad(n=19)\end{array}$ & $\begin{array}{l}\text { Severe polyhydramnios } \\
\qquad(n=15)\end{array}$ & p-value \\
\hline $\begin{array}{l}\text { Maternal age } \\
\text { (years) } \\
\text { Mean (SD) }\end{array}$ & $29(6)$ & $30(6)$ & $30(5)$ & 0.641 \\
\hline $\begin{array}{l}\text { Gestational age at diagnosis } \\
\text { (week) } \\
\text { Mean (SD) }\end{array}$ & $34(4)$ & $32(4)$ & $33( \pm 5)$ & 0.114 \\
\hline $\begin{array}{l}\text { AFI value (maximal) } \\
{[\mathrm{cm}]} \\
\text { Median (range) }\end{array}$ & $26(24-30)^{*}, * *$ & $32(30-34.5)^{* *}$ & $39(35-51)^{*}$ & $<0.001$ \\
\hline $\begin{array}{l}\text { Congenital infection } \\
\text { (pos./neg.) }\end{array}$ & $2 / 57$ & $0 / 19$ & $0 / 15$ & 1.0 \\
\hline $\begin{array}{l}\text { Diabetes during pregnancy } \\
\text { (pos./neg.) } \\
\text { (\%) }\end{array}$ & $\begin{array}{l}5 / 55 \\
(9.1)\end{array}$ & $\begin{array}{c}3 / 16 \\
(18.7)\end{array}$ & $\begin{array}{l}1 / 14 \\
(7.1)\end{array}$ & 0.494 \\
\hline $\begin{array}{l}\text { Gestational age at delivery } \\
\text { (week) } \\
\text { Mean (SD) }\end{array}$ & $39(2)$ & 37 (4) & $37(2)$ & 0.226 \\
\hline $\begin{array}{l}\text { Mode of delivery } \\
\text { Number } \\
(\%)\end{array}$ & $\begin{array}{l}\text { CS } 27(45 \%) \\
\text { VB } 27(45 \%) \\
\text { VE } 6(10 \%)\end{array}$ & $\begin{array}{l}\text { CC } 12(63.2 \%) \\
\text { VB } 5(26.3 \%) \\
\text { VE } 1(5.3 \%)\end{array}$ & $\begin{array}{l}\text { CC } 7(46.7 \%) \\
\text { VB } 4(26.7 \%) \\
\text { VE } 4(26.7 \%)\end{array}$ & 0.157 \\
\hline $\begin{array}{l}\text { Newborns birth weigh } \\
\text { [g] } \\
\text { Mean (SD) }\end{array}$ & $3510(675)$ & 2955 (1000) & $3230(735)$ & 0.154 \\
\hline
\end{tabular}

$\mathrm{CS}$ - cesarean section; VB - spontaneous vaginal birth; VE - vacuum extractor; $\mathrm{SD}$ - standard deviation. * $\mathrm{p}<0.05$ vs. severe polyhydramnios,

${ }^{* *} \mathrm{p}<0.05$ vs. moderate polyhydramnios 


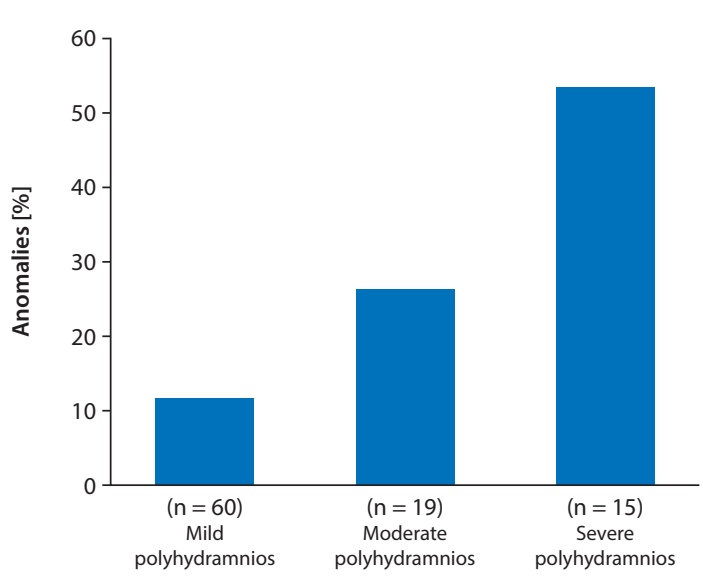

Figure 1. The frequency of fetal anomalies in patients with mild, moderate, and severe polyhydramnios

Among all studied groups, the general frequencies of fetal central nervous system and gastrointestinal tract anomalies were $2.1 \%$ and $5.3 \%$, respectively, including the two cases of fetal duodenal atresia, one of fetal ileus and the other of Dandy-Walker syndrome in patients with severe polyhydramnios.

In all patients with polyhydramnios, other fetal anomalies than malformations of the central nervous system or gastrointestinal tract were found in 13 (13.8\%) women. Among them, the most frequent was $\mathrm{CDH}$, which was found in three fetuses (3.2\%), including two in women with mild polyhydramnios and skeletal dysplasias, also diagnosed in three fetuses, but two in the group with severe polyhydramnios.

Trisomy 18 was the most frequently diagnosed genetic syndrome in patients with polyhydramnios (2.1\%).

The frequencies of all fetal anomalies in the three groups of patients are presented in Table 2.

\section{DISCUSSION}

It is well known, that polyhydramnios is associated with the increased risk of different fetal congenital anomalies [3-5].
In the population studied, the incidence of fetal malformations was approximately 10 times higher than the general prevalence of fetal congenital anomalies in Europe according to the European Surveillance of Congenital Anomalies [6].

The most frequent form of polyhydramnios was an idiopathic one, found in approximately $68 \%$ of patients. It is consistent with other literature data $[7,8]$.

Most of the studied patients were diagnosed with mild polyhydramnios, which usually represents more than $60 \%$ of pathology $[9,10]$. This form of polyhydramnios was also associated with the lowest frequency of congenital anomalies in our study which is consistent with data presented by other authors $[4,9,10]$. However the frequency of fetal anomalies in patients with mild polyhydramnios differed in our study from other data and was lower than that described by Pri-Paz et al. [4], but higher than that found by Dashe et al [10]. In severe polyhydramnios, both in our study and in other ones $[9,10]$, the prevalence of fetal malformations was the highest exceeding 50\%. The extremely high incidence of abnormal results (79.1\%) of fetal anatomy scan in fetuses of mothers with $\mathrm{AFI} \geq 35 \mathrm{~cm}$ was found by Pri-Paz et al. [4].

Interestingly, both in the whole studied population and in patients with severe polyhydramnios, we found lower prevalence of fetal central nervous system anomalies than in other studies $[4,11,12]$. More frequently, especially in severe polyhydramnios group, we found fetal gastrointestinal malformations, which was comparable to the incidence described by other authors $[4,11]$.

In comparison with the results of other studies [4, 11, $12]$, we did not find any case of cardiac malformation, which was the most frequently diagnosed anomaly in foetuses of mother with polyhydramnios, described by Pri-Paz et al. [4] and Boito et al. [12].

The fact of quite high incidence of $\mathrm{CDH}$ and skeletal dysplasia in fetuses of mothers with polyhydramnios was worth emphasizing. The first anomaly was rather more frequent

Table 2. Detailed anaylsis of all anomalies in three groups of patients

\begin{tabular}{|c|c|c|c|}
\hline & $\begin{array}{l}\text { Mild polyhdramnios } \\
\qquad(n=60)\end{array}$ & $\begin{array}{l}\text { Moderete polyhydramnios } \\
\qquad(n=19)\end{array}$ & $\begin{array}{l}\text { Severe polyhydramnios } \\
\qquad(n=15)\end{array}$ \\
\hline $\begin{array}{l}\text { Gastrointestinal tract anomalies } \\
\mathrm{n}(\%)\end{array}$ & Esophageal atresia -1 (1.7) & Esophageal atresia -1 (5.3) & $\begin{array}{c}\text { Duodenal atresia }-2(13.3) \\
\text { Ileus }-1(6.7)\end{array}$ \\
\hline $\begin{array}{l}\text { Central nervous system } \\
\text { anomalies } \\
\mathrm{n}(\%)\end{array}$ & Hydrocephalus -1 (1.7) & & Dandy-Walker syndrome -1 (6.7) \\
\hline $\begin{array}{l}\text { Other anomalies } \\
\mathrm{n}(\%)\end{array}$ & $\begin{array}{c}\mathrm{ES}-1(1.7) \\
\mathrm{CDH}-1(1.7) \\
\mathrm{GS}-1(1.7) \\
\mathrm{CHD}-1(1.7) \\
\text { Ovarian cyst }-1(1.7)\end{array}$ & $\begin{array}{c}\text { Fetal goiter }-1(5.3) \\
\text { NIH }-1(5.3) \\
\text { Skeletal dysplasia }-1 \text { (5.3) } \\
\text { ES }-1 \text { (5.3) }\end{array}$ & $\begin{array}{c}\text { Oral/palate cleft }-1(6.7) \\
\text { Skeletal dysplasia }-2(13.4) \\
\text { CDH }-1(6.7)\end{array}$ \\
\hline All (\%) & $7(11.7)$ & $5(26.3)$ & $8(53.3)$ \\
\hline
\end{tabular}

ES - Edwards syndrome; $\mathrm{CDH}$ - congenital diaphragmatic hernia; $\mathrm{GS}$ - gastroschisis; $\mathrm{NIH}$ - non-immune hydrops; $\mathrm{SD}$ - standard deviation 
in case of mild polyhydramnios and the second one in the group with severe polyhydramnios, which is consistent with other literature data [4, 12].

Results of our study indicate also a rare frequency of congenital infection as a cause of polyhydramnios. Among all patients we found only two cases with infection of Toxoplasma gondii (2.1\%). It is similar to the results of the larger study by Pasquini et al. [7] who found only $1 \%$ of patients with congenital infections and polyhydramnios, including two with Parvovirus B19 and one with Toxoplasma gondii. In both studies congenital infections were found only in patients with mild or moderate polyhydramnios.

In comparison with other studies [12,13] we observed fewer cases of diabetes in patients with polyhydramnios, most of them in the group with moderate polyhydramnios and only one in women with severe one. This result might be explained by better metabolic control in our diabetic group. Although the incidence of diabetes was approximately $10 \%$ in patients with polyhydramnios, it was approximately $20.9 \%$ and $14.9 \%$, respectively, as observed by Yefet et al. [13] and Boito et al. [12].

Like in other studies $[4,12]$, we found a low incidence of polyploidy in patients with polyhydramnios (2.1\%). In a study published by Pri-Paz [4] the most frequent chromosomal aberration was trisomy 18. Another quite frequent aneuploidy found in women with polyhydramnios is trisomy 21 [12]. The incidence of all genetic disorders in fetuses of women with polyhydramnios is higher and may exceed 13\% [12]. It includes, except aneuploidies, other rare genetic disorders, for example, single-gene disorders or microdeletion syndromes [12]. Lack of the information on the incidence of rare genetic diseases in our materials is a consequence of limited possibilities to perform molecular diagnostics in fetus.

\section{CONCLUSIONS}

The incidence of fetal congenital anomalies significantly increases with the degree of polyhydramnios, being most frequent in severe one and rather rare in a mild one.

Congenital malformations of the gastrointestinal tract are the most frequent congenital anomalies in patients with polyhydramnios, especially in women with severe polyhydramnios.
Polyhydramnios is associated with a quite high incidence of fetal $\mathrm{CDH}$ and skeletal dysplasia and a very low frequency of congenital infections.

The precise measurement of AFI is important because indicates on high or low risk of a presence of fetal congenital malformations what is crucial when counselling the patients.

\section{REFERENCES}

1. Stanescu AD, Banica R, Olaru G, et al. Idiopathic polyhydramnios and fetal gender. Arch Gynecol Obstet. 2015; 291(5): 987-991, doi: 10.1007/s00404-014-3504-1, indexed in Pubmed: 25288271.

2. Sagi-Dain L, Sagi S. Chromosomal aberrations in idiopathic polyhydramnios: A systematic review and meta-analysis. Eur J Med Genet. 2015; 58(8): 409-415, doi: 10.1016/j.ejmg.2015.06.010, indexed in Pubmed: 26186913.

3. Yeung Leung T, Hung Suen SS. Manipaulation of amniotic fluid volume:oligohydramnios and polyhydramnios. In: Kliby MD, Oepkes D, Johnson A. ed. Fetal therapy Scientific Basis and Critical Appraisal of Clinical Benefits. Cambridge Raven Press, New York 2013: 137-144.

4. Pri-Paz S, Khalek N, Fuchs KM, et al. Maximal amniotic fluid index as a prognostic factor in pregnancies complicated by polyhydramnios. UItrasound Obstet Gynecol. 2012; 39(6):648-653, doi: 10.1002/uog.10093, indexed in Pubmed: 21898637.

5. Morris RK, Meller CH, Tamblyn J, et al. Association and prediction of amniotic fluid measurements for adverse pregnancy outcome: systematic review and meta-analysis. BJOG. 2014; 121(6): 686-699, doi: 10.1111/1471-0528.12589, indexed in Pubmed: 24738894.

6. Dolk H, Loane M, Garne E. The prevalence of congenital anomalies in Europe. Adv Exp Med Biol. 2010; 686: 349-364, doi: 10.1007/978-90-4819485-8 20, indexed in Pubmed: 20824455.

7. Pasquini L, Seravalli V, Sisti G, et al. Prevalence of a positive TORCH and parvovirus B19 screening in pregnancies complicated by polyhydramnios. Prenat Diagn. 2016; 36(3): 290-293, doi: 10.1002/pd.4769, indexed in Pubmed: 26970557.

8. Magann EF, Chauhan SP, Doherty DA, et al. A review of idiopathic hydramnios and pregnancy outcomes. Obstet Gynecol Surv. 2007; 62(12): 795-802, doi: 10.1097/01.ogx.0000290349.58707.e0, indexed in Pubmed: 18005456.

9. Harman CR. Amniotic fluid abnormalities. Semin Perinatol. 2008; 32(4): 288 294, doi: 10.1053/j.semperi.2008.04.012, indexed in Pubmed: 18652930.

10. Dashe JS, McIntire DD, Ramus RM, et al. Hydramnios: anomaly prevalence and sonographic detection. Obstet Gynecol. 2002; 100(1): 134-139, indexed in Pubmed: 12100815.

11. Kleine RT, Bernardes LS, Carvalho MA, et al. Pregnancy outcomes in severe polyhydramnios: no increase in risk in patients needing amnioreduction for maternal pain or respiratory distress. J Matern Fetal Neonatal Med. 2016; 29(24): 4031-4034, doi: 10.3109/14767058.2016 1153060, indexed in Pubmed: 26948899.

12. Boito S, Crovetto F, Ischia B, et al. Prenatal ultrasound factors and genetic disorders in pregnancies complicated by polyhydramnios. Prenat Diagn. 2016; 36(8): 726-730, doi: 10.1002/pd.4851, indexed in Pubmed: 27247190.

13. Yefet E, Daniel-Spiegel E. Outcomes From Polyhydramnios With Norma Ultrasound. Pediatrics. 2016; 137(2): e20151948, doi: 10.1542/peds.20151948, indexed in Pubmed: 26755694. 